\title{
Influência da Temperatura e da Umidade Relativa do Ar na Esporulação de Magnaporthe grisea em Trigo
}

\author{
Kalíbia Jane P. Alves ${ }^{1}$ \& José Maurício C. Fernandes ${ }^{2}$ \\ ${ }^{1}$ Faculdade de Agronomia e Medicina Veterinária, Universidade de Passo Fundo, Cx. Postal 611, CEP 99001-970, \\ Passo Fundo, RS, e-mail: kalibiajane@yahoo.com.br; ${ }^{2}$ Embrapa Trigo, Cx. Postal 451, CEP 99001-970, \\ Passo Fundo, RS, e-mail: mauricio@cnpt.embrapa.br
}

(Aceito para publicação em 01/12/2006)

Autor para correspondência: José Maurício Cunha Fernandes

ALVES K. J. P. \& FERNANDES, J.M.C. Influência da temperatura e da umidade relativa do ar na esporulação de Magnaporthe grisea em trigo. Fitopatologia Brasileira 31:579-584. 2006.

\begin{abstract}
RESUMO
O fungo Magnaporthe grisea (Anamorfo Pyricularia grisea) é o agente causal da brusone do trigo (Triticum aestivum), uma doença limitante à cultura do trigo no Brasil em regiões produtoras localizadas acima do paralelo $24^{\circ} \mathrm{S}$. $\mathrm{O}$ objetivo do presente trabalho foi estudar o efeito da temperatura e da umidade relativa do ar na esporulação de $M$. grisea. O número médio de conídios foi determinado em ráquis de plantas de trigo previamente colonizados com o fungo e expostos em câmaras de crescimento sob temperaturas de 23 e $28^{\circ} \mathrm{C}$, e com umidade relativa do ar de $80,85,90,95$ e $100 \%$. A determinação do número de conídios produzidos foi feita após 24, 48, 72 e 96 horas de exposição em cada combinação de temperatura e umidade. Os efeitos da temperatura e da umidade foram significativos $(P<0.001)$, mas não o da interação. A produção de conídios também foi determinada sob condições naturais de ambiente onde se verificou flutuação da temperatura e da umidade relativa do ar. Os resultados do presente trabalho permitiram observar que quando a umidade relativa é elevada ( $\geq 90 \%$ ) e a temperatura se encontra ao redor de $28^{\circ} \mathrm{C}$, a produção de conídios de M. grisea é favorecida.
\end{abstract}

Palavras-chave adicionais: Triticum aestivum, Pyricularia grisea, fatores climáticos, modelos preditivos.

\begin{abstract}
Influence of temperature and relative air humidity on the sporulation of Magnaporthe grisea on wheat

The fungus Magnaporthe grisea (anamorph Pyricularia grisea) is the causal agent of wheat blast (Triticum aestivum), an important disease for the wheat crop in Brazil. The disease is more frequent in wheat producing regions above the parallel $24{ }^{\circ} \mathrm{S}$. The objective of the present work was to study the effect of temperature and relative air humidity in the sporulation of $M$. grisea. The average number of conidia was determined in raquis of wheat plants previously colonized by the fungus and exposed to growth chambers under temperatures of 23 and $28{ }^{\circ} \mathrm{C}$, and with relative humidity of $80,85,90,95$ and $100 \%$. The number of produced conidia was determined after 24, 48, 72 and 96 hours of exposure in each combination of temperature and humidity. The effect of the temperature and the humidity was significant $(\mathrm{P}<0.001)$, but not the interaction. The production of conidia was also determined under natural environment conditions where temperature and the relative humidity fluctuated. The results of the present work revealed that production of conidia of $M$. grisea was favored by the combination of high relative humidity $(\geq 90 \%)$ and temperature around $28^{\circ} \mathrm{C}$.
\end{abstract}

Additional keywords: Triticum aestivum, Pyricularia grisea, climatic factors, predictive models.

\section{INTRODUÇÃO}

Magnaporthe grisea (T.T. Hebert) M.E. Barr (anamorfo Pyricularia grisea Sacc.) é um patógeno largamente conhecido como o agente causal da brusone do arroz, considerada uma das ameaças à segurança alimentar no mundo (Valent, 2004). Entretanto, o impacto deste fungo está sendo verificado em outras espécies de gramíneas. Determinados biótipos do fungo tem sido encontrado associado à cultura da cevada (Hordeum vulgare L.), do trigo (Triticum aestivum L.), do milheto (Pennisetum americanum K. Schum.) e do azévem perene (Lolium perenne L.) para gramados de campos de golfe (Landschoot \& Hoyland, 1992; Valent \& Chumley, 1994).
$\mathrm{Na}$ cultura do trigo, a brusone foi relatada pela primeira vez no Brasil em 1985 (Igarashi et al., 1986). Atualmente, a doença ocorre com maior freqüência nos estados do Paraná, São Paulo, Goiás e Mato Grosso do Sul (Goulart et al., 1990; Lasca et al., 2001). Os sintomas da doença são percebidos em quase todas as partes da parte aérea da planta do trigo, mas principalmente nas espigas, as quais apresentam branqueamento total ou parcial da parte imediatamente superior à lesão, ocasionando esterilidade ou chochamento dos grãos (Goulart, 2000).

A brusone do trigo é considerada uma doença de ocorrência esporádica, provavelmente devido às condições ambientais e estágio fenológico da planta que precisam coincidir no tempo para que ocorra o estabelecimento e o 
progresso epidemia. As medidas de controle da brusone do trigo são precárias. Os fungicidas recomendados apresentam eficiência baixa, e as cultivares existentes são, na sua grande maioria, suscetíveis.

Um grande volume de trabalhos de modelagem de epidemias da brusone foi conduzido para a cultura do arroz (Kim, 2001). Porém, a informação é escassa sobre a epidemiologia da brusone do trigo, como o efeito de fatores ambientais na esporulação do patógeno. A informação epidemiológica é importante para o estabelecimento de medidas de controle, especialmente quando se busca desenvolver modelos de previsão para apoiar a tomada de decisão sobre o momento de aplicação de fungicidas. Tais dados podem ser mais facilmente obtidos em experimentos sob condições controladas, mas que podem não refletir o fenômeno que ocorre sob condições naturais.

O objetivo deste estudo foi o de verificar e comparar o efeito de fatores ambientais na produção de conídios de $M$. grisea, em condições controladas e ao ar livre.

\section{MATERIAL E MÉTODOS}

Os experimentos foram conduzidos no Laboratório de Fitopatologia e na área Experimental da Empresa Brasileira de Pesquisa Agropecuária - Embrapa Trigo, localizado em Passo Fundo, Estado do Rio Grande do Sul, no período de maio de 2004 a fevereiro de 2005.

Unidades experimentais: Foram utilizadas espigas de plantas de trigo da cultivar BR 23 cultivadas em vasos (5 L) contendo cinco plantas por vaso. Um conjunto de 150 vasos foi estabelecido para os experimentos. Espigas em estágio de crescimento 69 (antese completa) da escala de
Zadoks (Zadoks et al., 1974) e em seguida armazenadas em saco de papel sob frio a $-18{ }^{\circ} \mathrm{C}$. Antes da aplicação do tratamento, as espigas foram expostas à temperatura ambiente por 20 minutos. De cada espiga, destacaram-se todas as espiguetas da raque. Após, realizou-se a assepsia das raques em solução de hipoclorito de sódio ( $2 \%$ ) por três minutos, seguida de lavagem com água destilada.

Procedimento de inoculação: Em cada um dos experimentos foi usada uma suspensão de conídios de $M$. grisea $\left(25 \times 10^{4}\right.$ conídios. $\left.\mathrm{mL}^{-1}\right)$ produzidos em meio de aveia ( $60 \mathrm{~g}$ de aveia e $15 \mathrm{~g}$ de ágar para $1000 \mathrm{~mL}$ de meio de cultura), acrescido de antibióticos (sulfato de estreptomicina e sulfato de neomicina ambos a $0,5 \mathrm{~g}$ em $1.000 \mathrm{~mL}$ de água destilada) e Tween $20(0,1 \%)$. As raques foram imersos nesta suspensão de conídios, seguido de agitação por três minutos. Na seqüência, as raques foram dispostos em caixas plásticas do tipo gerbox $(11,5 \times 11,4 \times 3,4 \mathrm{~cm}$ de altura) em uma câmara de fluxo laminar, em número de três raques por caixa. $\mathrm{O}$ fundo das caixas foi forrado com papel de filtro umedecido com água destilada. Um bastão de vidro em forma de "V" e lâminas foram utilizados para suspender as raques dentro do gerbox (Figura 1A). $\mathrm{O}$ material foi mantido em câmara de crescimento, sob temperatura de $25^{\circ} \mathrm{C}$, por 18 horas. Após, as raques foram retirados e colocados para secagem por uma hora em câmara de fluxo laminar.

Avaliação de produção de conídios: As raques foram sendo retirados para avaliação segundo os tempos de tratamento. A raque foi colocado em um tubo de ensaio com tampa de baquelite com $5 \mathrm{~mL}$ de água destilada e agitado por um minuto. Dessa suspensão foi retirada uma alíquota
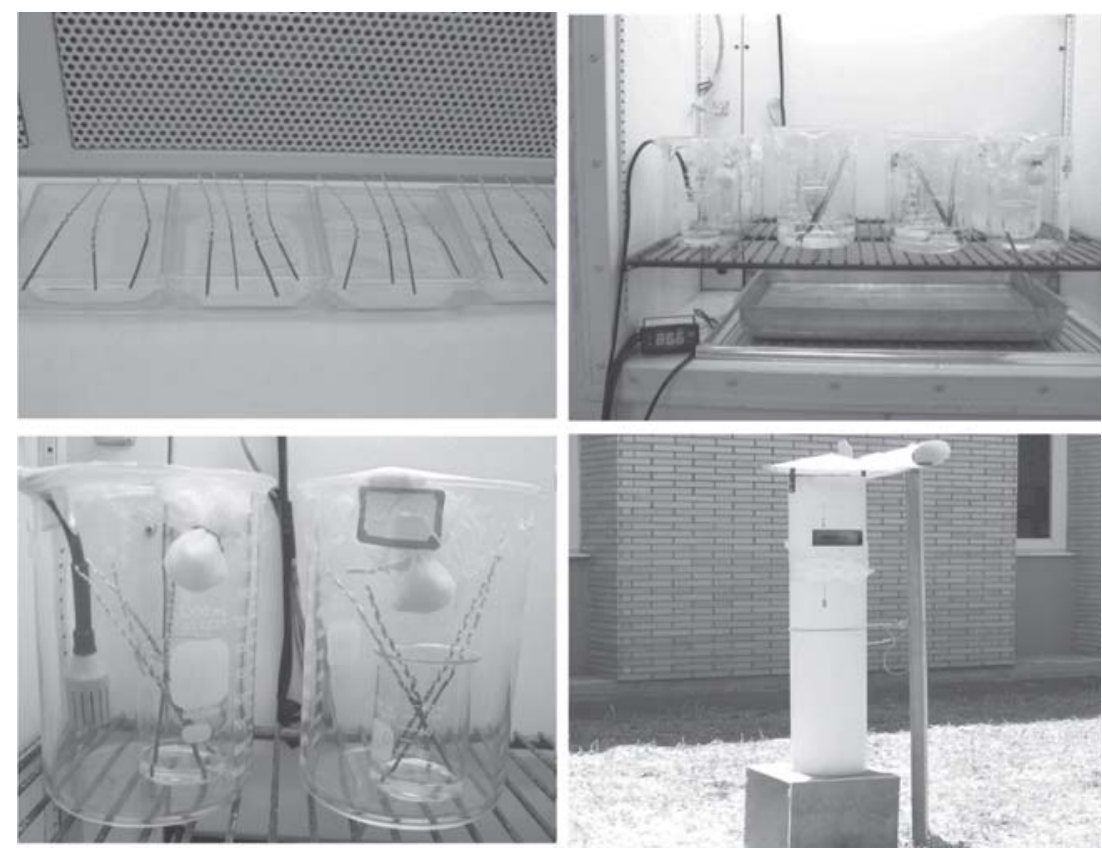

FIG. 1 - A. Raque de plantas de trigo logo após a inoculação com uma suspensão de conídios de M. grisea; B. Raque no interior da câmara de crescimento com condições controladas de temperatura; C. Sensor eletrônico de umidade relativa do ar dentro de Beckers contendo as raques; D. Dispositivo usado de abrigo para as raques e sensor eletrônico expostos ao ar livre. 
de 0,2 $\mathrm{mL}$ a qual foi colocada em câmara de Neubauer. Em microscópio ótico realizou-se a contagem do número de conídios em dois campos de leitura, anotando-se a média das duas contagens.

Experimentos em câmara de crescimento: $\mathrm{O}$ efeito da temperatura e da umidade relativa na taxa de produção de conídios de $M$. grisea em raques de plantas de trigo, colonizadas com M. grisea, foi avaliado em duas câmaras de crescimento com temperaturas monitoradas com termômetros de mercúrio. O delineamento experimental foi de blocos totalmente casualizados com fatorial $2 \times 4$ (dois níveis de temperatura e quatro níveis de umidade relativa). As temperaturas foram de 23 e $28{ }^{\circ} \mathrm{C}$, respectivamente. No início de cada experimento, foi aleatoriamente escolhida a câmara para cada temperatura. Foram utilizadas 10 repetições, cada qual constituída por um conjunto de quatro raques.

As câmaras de crescimento (Percival I - $30 \mathrm{BL}$, $1,15 \times 0,78 \mathrm{~m}$ ) foram programadas com a temperatura e o fotoperíodo de acordo com o tratamento. A iluminação nas câmaras foi fornecida por lâmpadas fluorescentes Osram Universal $20 \mathrm{~W}$, distanciadas $40 \mathrm{~cm}$ da superfície dos Beckers com fotoperíodo de $12 \mathrm{~h}$.

Em cada condição de temperatura foram colocados quatro Beckers, com um nível de umidade relativa (UR) $85,90,95$ e $100 \%$, respectivamente. Esses foram obtidos através da manutenção de água pura dentro do Becker ou pela fixação de um pequeno saco de gaze, contendo diferentes quantidades de cloreto de sódio $(\mathrm{NaCl})$ na parede interna do Becker (Tabela 1). Os Beckers foram selados com filme plástico e vedados com parafilme, sendo colocado um conjunto de quatro raques em cada Becker (Figura 1B). Os regimes de UR e de temperatura foram continuamente monitorados por sensores eletrônicos (Full Gauge MT530R), colocados dentro dos Beckers (Figura 1C). O $\mathrm{NaCl}$ em cada um dos sacos de gazes nos tratamentos foi trocado após 48 horas para garantir ausência da saturação. Para a contagem do número de conídios foi retirado uma raque após 24, 48, 72 ou 96 horas de incubação de cada Becker.

TABELA 1 - Condição experimental usada para incubação de ráquis de trigo inoculados com conídios de Magnaporthe grisea em ambiente controlado

\begin{tabular}{cccc}
\hline \hline $\begin{array}{c}\text { Temperatura de } \\
\text { incubação }\left({ }^{\circ} \mathbf{C}\right)\end{array}$ & $\begin{array}{c}\text { Umidade relativa } \\
\text { dentro do Becker }(\%)\end{array}$ & Água $(\mathrm{mL})$ & $\mathbf{N a C l}(\mathrm{g})$ \\
\hline $\mathbf{2 3}$ & $78 \pm 2$ & - & 15 \\
& $82 \pm 2$ & - & 06 \\
& $86 \pm 2$ & - & - \\
& 99 & 200 & \\
$\mathbf{2 8}$ & $86 \pm 2$ & - & 15 \\
& $87 \pm 2$ & - & 06 \\
& $95 \pm 2$ & - & - \\
& 99 & 200 & - \\
\hline
\end{tabular}

Experimentos em campo: Um conjunto de dez raques colonizadas com o $M$. grisea foi posicionado verticalmente em um abrigo de cano de PVC com 200 mm de diâmetro (Figura 1D). Na base do cano foi colocado um vaporizador (Humidifier Ultrasonic Vicks V-5100) com a finalidade de prover contínua umidade relativa mais alta no ambiente ao redor das raques. Um sensor (Squitter UTReg S1615) foi colocado próximo às raques e programado para registrar a temperatura e a umidade relativa em intervalos de dez minutos.

Cada uma das 10 raques foi retirada após 24, 48, $72,96,120,144,168,192,216$ ou 240 horas de incubação no abrigo. A contagem dos conídios foi feita conforme anteriormente descrito. O delineamento experimental foi inteiramente casualizado com três repetições, cada qual em diferentes intervalos de tempo no período compreendido entre dezembro de 2004 e janeiro de 2005.

Análise dos dados: Os dados dos experimentos em câmara de crescimento foram submetidos a dois tipos de análise para examinar o efeito da temperatura e da umidade relativa na produção de conídios. Na primeira, estimativas da média populacional em raques individuais de plantas de trigo foram transformadas usando-se a função do logaritmo natural. Foi feita uma análise de regressão, utilizando-se a média dos valores transformados para cada uma das combinações de temperatura e umidade relativa e o número de horas de exposição. O valor do ângulo de inclinação obtido para cada uma das retas foi usado como variável dependente na análise da variância para determinar o efeito da temperatura, da umidade relativa e da interação.

$\mathrm{Na}$ segunda análise, os dados foram transformados para o logaritmo natural nos valores de tempo (hora) e para o logito $(\log (\mathrm{y} / \mathrm{k}-\mathrm{y}))$ para os valores de contagem de número de conídios (y). O valor de $\mathrm{k}$ corresponde ao assimptótico superior. A taxa de produção de conídios (incremento proporcional no número de conídios por hora) foi calculado para cada valor de umidade relativa independentemente da temperatura. Os dados transformados foram usados para a análise de regressão. Estimativas da taxa de produção de conídios obtidas dos dados transformados foram usadas na regressão contra os valores transformados de tempo de exposição e comparado a inclinação das retas.

No experimento de campo, o número de conídios (y) em cada raque foi transformado para o logaritmo natural (y). As estimativas da taxa de produção de conídios durante o período de condução do experimento foi calculada usando a função exponencial na forma

$$
\mathrm{r}=1 / \text { número de horas } *\left[\log \left(\mathrm{y}_{\text {número de horas }}\right)-\log \left(\mathrm{y}_{\text {zero }}\right)\right.
$$

onde $y_{z e r o}$ é a média do número de conídios no início do período e $y_{\text {numero de horas }}$ é a média do número de conídios no fim do período. A taxa de formação de conídios foi relacionada com o acumulado de graus dia $(\mathrm{tb}=10)$ desde que a umidade relativa fosse maior ou igual a $93 \%$ (Kim, 2001). 


\section{RESULTADOS}

Experimento em câmara de crescimento: As diferentes quantidades de $\mathrm{NaCl}$ propiciaram diferentes valores de umidade relativa do ar dentro dos Beckers, conforme descrito por Rossi et al. (2001). O fungo M. grisea colonizou os ráquis de espigas de trigo, produzindo conídios que foram recuperados através de lavagens durante a condução do experimento. Os dados comparativos obtidos da produção de conídios em ráquis de trigo nas combinações de temperatura e umidade relativa são apresentados na Figura 2. Em geral, o número de conídios aumentou com o tempo de exposição, principalmente nos tratamentos onde a umidade relativa era mais elevada ( $\geq 90 \%$ ). O padrão de produção de conídios foi similar entre as repetições, ou seja, poucos conídios foram produzidos nas primeiras 48 horas e aumentando de forma exponencial até as 96 horas de exposição. Novamente, isto foi mais evidente nos tratamentos em que a umidade relativa era elevada.

A análise da variância dos valores do ângulo de inclinação da reta mostrou um efeito altamente significativo $(P<0,0001)$ da temperatura e da umidade relativa, mas um efeito não significativo da interação. A análise de regressão dos dados transformados da contagem de conídios em relação ao tempo de exposição para cada um dos níveis de umidade resultou em modelos lineares com coeficientes de regressão significantes $(\mathrm{P}<0.05)$. Além disso, a comparação da inclinação das retas revelou que os coeficientes de regressão são similares para todos os níveis de umidade. Conídios de $M$. grisea foram observados a partir de 24 horas de exposição. A produção de conídios foi maior e ocorreu mais rapidamente aos $28{ }^{\circ} \mathrm{C}$ do que aos $23{ }^{\circ} \mathrm{C}$ (Figura 2).

Experimento de campo. Como era esperado, as temperaturas e a umidade relativa oscilaram ao redor de um dia. A seqüência temporal das repetições foi eficiente para aumentar a amplitude da variação da temperatura e da umidade. Por exemplo, o número de graus dia com a temperatura base de $10{ }^{\circ} \mathrm{C}$ foi de 161,132 e 138, respectivamente, nas repetições 1 , 2 e 3 . O uso de um umidificador para suplementar a umidade do ar no ambiente ao redor das raques se mostrou eficiente para elevar os valores de umidade relativa bem acima de $80 \%$, umidade verificada sem o uso do umidificador nos período em que o experimento foi conduzido. A taxa de produção de conídios apresentou correlação $(r=0,89)$ com o cumulativo de graus hora $\left(\mathrm{Tb}=10^{\circ} \mathrm{C}\right)$ quando a umidade relativa era $\geq$ 93\% (Figura 3).

\section{DISCUSSÃO}

Os resultados deste estudo confirmam o efeito da temperatura e umidade relativa do ar altas na produção de

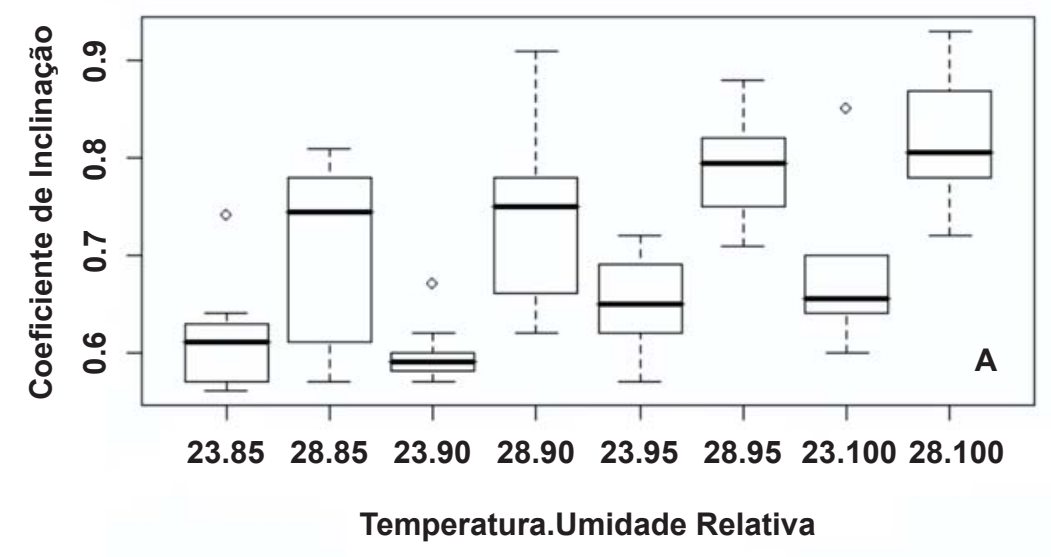

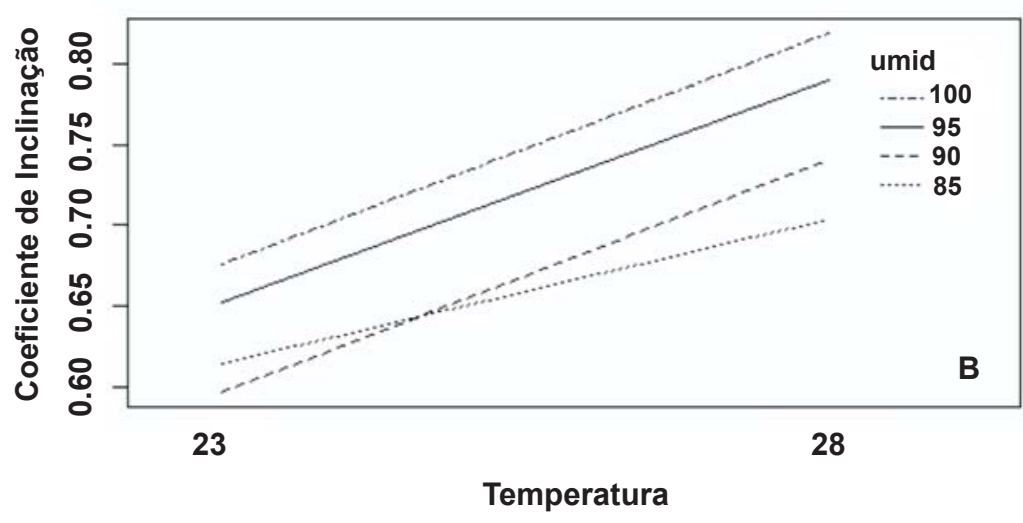

FIG. 2 - A. Diagramas de caixas ilustrando os valores do coeficiente de inclinação encontrados para cada uma das regressões da combinação temperatura e umidade em relação à duração do período de exposição; B. Representação gráfica da interação entre a temperatura e umidade. 


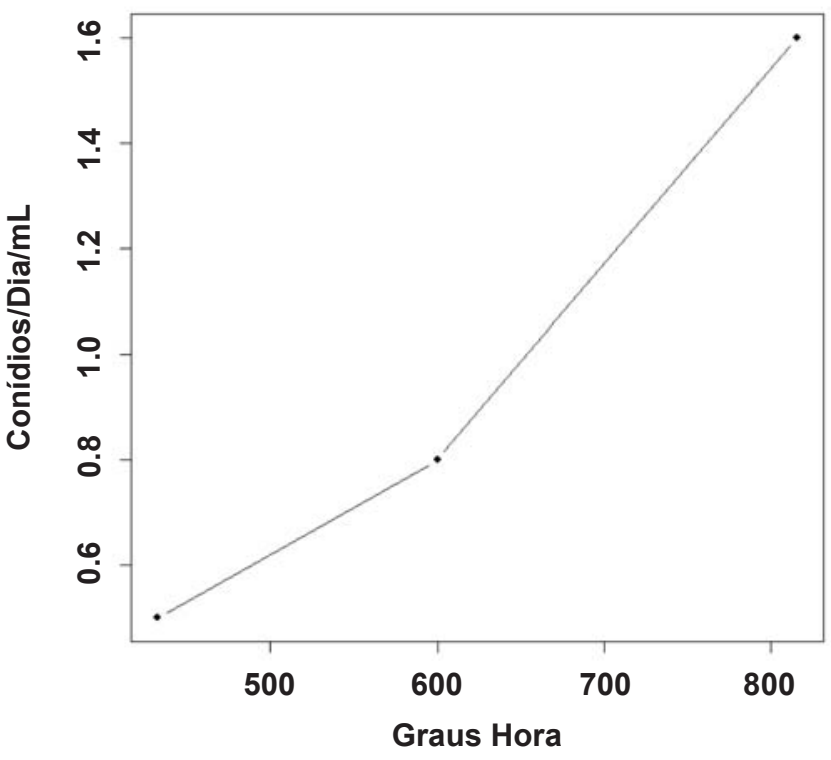

FIG. 3 - Relação entre estimativas da taxa intrínseca de formação de conídios de Magnaporthe grisea em raques de plantas de trigo previamente colonizadas com o patógeno e o número de graus hora calculado usando uma temperatura base de $10{ }^{\circ} \mathrm{C}$ desde que a umidade relativa fosse $\geq 93 \%$.

conídios de M. grisea. Abundante esporulação foi observada tanto nos experimentos controlados como em condições de campo quando a temperatura se manteve ao redor de $28{ }^{\circ} \mathrm{C}$ e umidade relativa de 95 a $100 \%$. Estes resultados estão de acordo com o observado para $M$. grisea em arroz (Webster \& Gunnel, 1972; Kim, 2001) e em gramados, onde a temperatura de $28{ }^{\circ} \mathrm{C}$ foi a mais favorável para o desenvolvimento da brusone (Uddin et al., 2003).

Uma relação estreita entre os dados climatológicos e o número de conídios amostrados do ar entre os meses de julho e outubro foi relatado na Espanha. Nos anos de 2002 e 2003 uma grande quantidade de conídios foi observada quando a umidade relativa se manteve acima de $95 \%$ e temperaturas acima de $26{ }^{\circ} \mathrm{C}$ (Castejón-Muñoz et al., 2004).

Hemmi \& Imura (1939) determinaram que em lesões de bruzone em arroz, os conidióforos do fungo cresceram e esporularam quando a umidade relativa foi maior ou igual a $93 \%$ e a temperatura se encontrava na amplitude de 15 a $35^{\circ} \mathrm{C}$ (Kato \& Sasaki, 1974; Arai \& Yoshino, 1987).

Em um estudo realizado na Coréia do Sul, Calvero et al. (1996) observaram que dias consecutivos com UR $\geq$ $80 \%$, número de dias com UR $\geq 80 \%$, dias consecutivos com precipitação pluvial e número de dias com precipitação acima de $84 \mathrm{~mm}$ por dia foram variáveis importantes para a previsão da brusone na cultura do arroz.

Segundo Koizumi \& Kato (1991), a taxa de produção de conídios segue uma distribuição normal com desvio padrão igual a 1,0. A taxa de esporulação máxima ocorre quando a temperatura foi de $27^{\circ} \mathrm{C}$. Nesta condição, o número de horas acumuladas até a produção de conídios foi 7,5 horas. Kim (2001) desenvolveu um modelo de simulação da brusone do arroz onde a produção de novos conídios de $M$. grisea é função da temperatura e do número de horas com umidade relativa maior que $93 \%$.

Weber (comunicação pessoal) observou no ano de 2001 no município de Londrina-PR o progresso de uma epidemia severa de brusone em campos de trigo, que iniciaram no estádio de espigamento ao redor do dia 15 de maio daquele ano. A incidência de brusone nas espigas era de $100 \%$ no dia 16 de junho. Analisando-se os dados climáticos do município de Londrina (Simepar, 2006), observou-se que, durante o estádio do florescimento do trigo, ocorreram dois períodos de 7 dias consecutivos de chuva. Neste período, a temperatura máxima foi de $24{ }^{\circ} \mathrm{C}$ nos dias com chuva e $28^{\circ} \mathrm{C}$ nos dias sem chuva, enquanto que a umidade relativa média foi de $89 \%$ para todo o período. Os resultados obtidos no presente estudo indicam que tais condições climáticas favoreceriam a produção de conídios de $M$. grisea em tecidos previamente colonizados, o que poderia explicar a explosão da epidemia da brusone no trigo. A informação epidemiológica obtida com isolados regionais de $M$. grisea será útil para o desenvolvimento de modelos para a previsão de risco de epidemias de brusone em trigo. O desenvolvimento de um modelo de previsão de epidemias da brusone no trigo poderá auxiliar em avaliações de o risco do desenvolvimento da doença, na medida em que as plantas de trigo se aproximam do estágio do espigamento. A experiência mostra que este é o estágio onde a doença pode causar o maior impacto para a cultura do trigo e, portanto, onde deverá ser tomada a decisão de usar fungicidas. Além disso, o modelo também poderá auxiliar no estabelecimento do zoneamento da cultura do trigo visando minimizar os riscos de epidemias de brusone no trigo.

\section{REFERÊNCIAS BIBLIOGRÁFICAS}

ARAI, N. \& YOSHINO, R. Studies on the sporulation of rice blast fungus. 1. Relation between sporulation and temperature. Annals of the Phytopathological Society of Japan 53:371-372. 1987.

CALVERO JUNIOR, S.B., COAKLEY, S.M. \& TENG, P.S. Development of empirical forecasting models for rice blast based on weather factors. Plant Pathology 45:667-668. 1996.

CASTEJÓN-MUÑOZ, M., LARA-ÁLVAREZ I. \& AGUILARPORTERO M. Climate influence over air content of Pyricularia oryzae conidia and symptomatology of rice crop in Southern Spain. In: Aldo Ferrero and Francesco Vidotto (Ed.) Challenges and Opportunities for Sustainable Rice-Based Production Systems. Torino. Italy, 2004. p. 10 (Abstract)

GOULART, A.C.P., PAIVA, F.A. \& MESQUITA, A.N. Ocorrência da brusone (Pyricularia oryzae) do trigo (Triticum aestivum) em 
Mato Grosso do Sul. Fitopatologia Brasileira 15:112-114. 1990.

GOULART, A.C.P. Perdas no rendimento de grãos de trigo causadas por Pyricularia grisea nos anos de 1991 e 1992 no Mato Grosso do Sul. Summa Phytopathologica 26:279-282. 2000.

HEMMI, T. \& IMURA, J. On the relation of air-humidity to conidial formation in the rice blast fungus, Pyricularia oryzae, and characteristics in the germination of conidia production by the strains showing different pathogenicity. Annals of the Phytopathological Society of Japan 9:147-156. 1939.

IGARASHI, S., UTIAMADA, C.M., IGARASHI, L.C., KAZUMA, A.H. \& LOPES, R.S. Pyricularia em trigo. 1. Ocorrência de Pyricularia sp. no estado do Paraná. Fitopatologia Brasileira 11:351-352. 1986.

KATO, H. \& SASAKI, T. Epidemiological studies of rice blast disease, with special reference to reproductive process in lesions on rice plants and disease forecast. Bulletin of the National Institute of Agriculture Science Service 28:1-61. 1974.

KIM, K.R. Weather - Driven models for rice leaf blast and their implementation to fore cast disease development on the near real - time basis. (Doctoral Thesis). Seoul. 2001.

KIM, C.K., MIN, H.S. \& YOSHINO, R. Epidemiological studies of rice blast disease caused by Pyricularia oryzae Cavara III. Diurnal pattern of conidial release and dispersal under the natural conditions. Annals of the Phytopathological Society of Japan 56:315-321. 1990.

KOIZUMI, S. \& KATO, H. Dynamic simulation of blast epidemics using a multiple canopy spore dispersal model. In: Teng, P.S.
(Ed.), Rice Blast modeling and Forecasting. Manila. Philippines. International Rice Research Institute. 1991. p.75-88.

LANDSCHOOT, P.J. \&. HOYLAND, B.F. Gray leaf spot of perennial ryegrass turf in Pennsylvania. Plant Disease 76:12801282. 1992.

LASCA, C.C., VALARIN, P.J. \& VECHIATO, M.H. Localização dos fungos Pyricularia oryzae e Helminthosporium oryzae em sementes de arroz e controle por meio de tratamento com fungicidas. Fitopatologia Brasileira 12:154. 1987. (Resumo)

ROSSI, V., RAVANETTI, A., PATTORI, E. \& GIOSUÈ, S. Influence of temperature and humidity on the infection of wheat spikes by some fungi causing fusarium head blight. Journal Plant Phytopathology 83:189-198. 2001.

UDDIN, W., SERLEMITSOS, K. \& VIJI, G. A temperature and leaf wetness duration-based model for prediction of gray leaf spot of perennial ryegrass turf. Phytopathology 93:336-343. 2003.

VALENT, B. Plant disease: Underground life for rice foe. Nature 431:516-517. 2004.

VALENT, B. \& CHUMLEY, F.G. Avirulence genes and mechanisms of genetic instability in the rice blast fungus. In: Zeigler, R.S., Leong, S.A. \& Teng, P.S. (eds.) Rice Blast Disease. Cambridge. Cambridge University Press. 1994. pp. 111-134.

WEBSTER, R.Y. \& GUNNELL, P.S. Compendium of rice diseases. Saint Paul MN. APS Press. 1992.

ZADOKS, J.C., CHANG, T.T. \& KONZAK, C.F. A decimal code for the growth stages of cereals. Weed Research 14:415-421. 1974. 